\title{
Frequency Stability Analysis in Low Frequency AC Systems for Renewables Power Transmission
}

\author{
J. Dong, A.B. Attya and O. Anaya-Lara \\ Department of Electronic and Electrical Engineering, University of Strathclyde \\ 16 Richmond Street, G1 1XQ Glasgow, UK \\ jiaji.dong@strath.ac.uk
}

\begin{abstract}
The foreseen high penetration levels of wind energy will have serious implications on frequency stability, hence developed control methods of wind turbine and alternative technologies including energy storage should enable the provision of frequency support by wind power. Active research is ongoing to investigate the possibility of collecting and transmitting offshore wind power through low frequency alternating current systems (LFAC). This paper develops a novel method to enhance frequency support capability of generators connected to a LFAC system. The leveraged frequency regulation ability of the generators at LFAC system is emphasized. The voltage is proportional to the frequency of the LFAC system, so that the transformers can be protected when frequency drops. Then the generators at LFAC system acquire sufficient time for frequency regulation. In this paper, a hydro generator at LFAC system is regarded as an energy storage plant, which is connected to the LFAC system rather than normal frequency grid.
\end{abstract}

Index Terms- Frequency regulation, Low frequency AC systems (LFAC), hydropower, wind power.

\section{INTRODUCTION}

The high penetration levels of wind energy will challenge system stability, which will cause voltage fluctuation, harmonics, frequency deviations and power flow congestions $[1,2]$. Recently, there are many methods to alleviate such challenges, where batter energy storage is a key to resolve active power imbalance problem, but there is still some financial barriers to expand the integration of energy storage, mainly battery-based stations [3-5]. Demand side management is an economical alternative, but since the penetration levels of wind increase, more curtailable load is required, which may influence users' behavior in some extent [6-8]. FACTS based on power electronics expand transmission capacity of existing infrastructure and alleviate power flow congestions, hence more wind energy could be integrated into grid [9-11].

Low Frequency AC system (LFAC) is also known as the Fractional Frequency Transmission System (FFTS). This idea was raised by Wang in 1990s [12, 13]. Compared to high voltage direct and alternating current (HVDC and HVAC), LFAC has economic advantages, when the distance to shore is between $50 \mathrm{~km}$ to $200 \mathrm{~km}$ [14-17]. Most papers focus on the simulation of frequency changer including transformer saturation ability and thyristor-based cyclo-converters. In this paper, VoltageSourced Converter (VSC) is integrated to step down the frequency to match the LFAC.

It is preferred to run hydropower synchronous generators at lower speeds compared to thermal power plants due to the nature of the machine stator, which is commonly a salient one in hydro generators [18]. Hence this paper integrates a hydropower plant at LFAC (50/3 $\mathrm{Hz}$ in this paper) to act as an energy storage station. This makes full use of the LFAC system inertia and potential frequency regulation ability of hydro generators, so that more renewable energy can be collected and transmitted through LFAC system with an improved capability to provide frequency ancillary services $[16,19,20]$. The LFAC system will achieve a compromise between the sensitivity of normal frequency synchronous generators, which are more vulnerable to large frequency deviation and HVDC links which are decoupled from grid frequency fluctuations. The frequency stability at utility grid $(50 \mathrm{~Hz}$ in this paper) systems is of higher priority than at LF systems. Thus, frequency deviation margin at LFAC system is relatively higher compared to utility grid.

In this context, the paper proposes a new concept to enhance frequency regulation at utility grid utilizing the generators at LFAC system to allow 'bonus time' to conventional generators at utility grid to respond to frequency events. This concept could enable the wind power to provide frequency support, and also improves the recovery period of wind turbines (e.g. recovery to nominal rotor speed in case of kinetic energy extraction [21]) after they provide frequency support to avoid the excavation of further events.

\section{METHODLOGY}

LFAC is used for long distance and large scale power transmission. VSC-converters are integrated to connect LFAC system and utility grid via High Voltage Direct Current links (HVDC). Hence, frequency events at each system do not have an impact on each other, since they are decoupled through the HVDC link. In addition, this reflects the possibility of having a wind power cluster connected via HVDC link, however the generation assets at LFAC system are still able to provide frequency support, on behalf or in coordination with the wind power cluster. Frequency events can be tolerated at LFAC system to the favor of securing active power support to the 
utility grid. Relatively larger frequency drops could be allowed at LFAC system, if all the equipment such as generators, transformers, power transmission lines and VSC can tolerate this frequency event. In utility grid, the frequency regulation is limited by the finite time, because it has to comply with more strict frequency deviations margin and time frame according to grid code [22].

\section{A. Bonus time}

Bonus time is the additional time to be provided for frequency support at utility grid. The main idea is to allow a certain margin of frequency drop at the LFAC system to provide active power surge to the utility grid and tackle the frequency incident at the utility grid (i.e. mitigate frequency nadir and rate of change of frequency; ROCOF). To illustrate this concept, an assumption is made where an identical frequency event happens at two systems one is LFAC and the other is NFAC (i.e. per unit parameters of generators, transformers and power transmission lines are identical), hence the p.u. values of ROCOF at both systems are equal. The bonus time ( $\left.\mathrm{T}_{\text {bonus }}\right)$ can be obtained using (1);

$$
T_{\text {bonus }}=\frac{f_{L F}^{o}-f_{L F}^{c}}{\operatorname{ROCOF}_{L F}}-\frac{f_{N F}^{o}-f_{N F}^{c}}{\operatorname{ROCOF}_{N F}}
$$

where $\mathrm{f}_{\mathrm{LF}}^{\mathrm{o}}$ and $\mathrm{f}_{\mathrm{NF}}^{\mathrm{o}}$ are the nominal frequencies at LFAC system and NFAC system respectively, while $\mathrm{f}_{\mathrm{LF}}$ and $\mathrm{f}_{\mathrm{NF}}^{\mathrm{c}}$ are the critical frequencies, $\mathrm{ROCOF}_{\mathrm{LF}}$ and $\mathrm{ROCOF}_{\mathrm{NF}}$ are the ROCOFs at LFAC system and NFAC system respectively. When $\mathrm{f}_{\mathrm{LF}}^{\mathrm{c}}<\mathrm{f}_{\mathrm{NF}}^{\mathrm{c}}, \mathrm{T}_{\text {bonus }}>0$ which allows more time to synchronous generators at utility grid to provide frequency support and mitigate the impact of reduced inertia due to the integration of wind energy.

Bonus time can be produced by increasing the total system inertia constant $(\mathrm{H})$ at LFAC system, i.e. large rotating mass levels up the system inertia and/or reducing $\mathrm{f}^{\mathrm{c}} \mathrm{LF}$. As an illustration, the NFAC system can operate within $49.5-50.5 \mathrm{~Hz}$ as statutory limits, comparably, LFAC system can be operated within 16.5-16.8 Hz. Likewise, when the frequency range at LFAC system is $(16-17.3 \mathrm{~Hz})$, it is equivalent to $(48-52 \mathrm{~Hz})$ at the NFAC $50 \mathrm{~Hz}$ system. This means that frequency margins at LFAC system are slightly refrained from grid code requirements i.e. the LFAC system is considered to be 'behind the meter'. The adaptability of the equipment at LFAC system to tolerate larger frequency drops is investigated through the next sections.

\section{B. Cooperation enhancement}

Cooperation enhancement provides a new control strategy to make all equipment change operating state to support each other instead of each element individually. To most of the transformers at LFAC system, the power flow is unidirectional, from hydro and wind generators to frequency converter side. The primary voltage of the transformer is obtained using (2);

$$
\begin{aligned}
& e=4.44 \cdot f \cdot n \cdot B \cdot A \\
& U_{T}=U_{G} \approx e
\end{aligned}
$$

where $\mathrm{U}_{\mathrm{T}}, \mathrm{U}_{\mathrm{G}}$, and $e$ are the primary voltage of the transformer, output voltage and induced electromotive force of the synchronous generator respectively. System frequency (f) has direct impact on B and A which are the number of turns, magnetic field density and area of the coil respectively.

$\mathrm{P}_{\mathrm{T}}$ is the maximum active power of the transformer, which can be assumed proportional to $U_{G}$ since the excitation current $\left(i_{m}\right)$ is almost constant. In cooperation enhancement control depicted in Fig.1, when frequency drops, $\mathrm{U}_{\mathrm{T}}$ is controlled to be proportional to frequency by adjusting field voltage $\left(\mathrm{U}_{\mathrm{f}}\right)$, so that the transformer is not saturated. The primary voltage of the transformer, according to cooperation enhancement, is curtailed to 0.94 per unit, hence The $\mathrm{P}_{\mathrm{T}}$ is limited, but the actual transferred power is not amended as long as it does not violate the curtailed value of $\mathrm{Pm}_{\mathrm{T}}$. Consequently, the proposed cooperation enhancement control at LFAC system, $\mathrm{P}_{\mathrm{T}}$ of transformer is proportional to frequency according to (2), while the delivered power is not influenced, when the transformer is not under full loading condition, where a numerical example is presented in Table I.

\section{TEST SYSTEMS}

Two Matlab®/Simulink models are developed to compare the frequency regulation of systems with/without LFAC frequency support. Both models rely on the accredited SimPowerSystems examples of Hydro generator and VSC-HVDC transmission with three-level Neutral Point Clamped (NPC) VSC with single phase carrier Sinusoidal Pulse Width Modulation (SPWM) switching. The integrated power electronics converters models are detailed and accurate not average or phasor models. Active and reactive power control is adopted in converter station at hydro side, meanwhile, DC voltage and reactive power control is adopted in converter station at utility grid. The simulation time step is $7 \mu$ s to capture all the system transients. And this is the first time to research the frequency transient stability of LFAC systems including hydro generator and VSC station according to authors' knowledge.

TABLE I. KEY PARAMETERS VALUES BEFORE AND DURING EVENT

\begin{tabular}{c|c|c}
\hline Parameter & Initial values & During frequency drop \\
\hline frequency & 1 per unit & 0.94 per unit \\
\hline Magnetic flux density & 1 per unit & 1 per unit \\
\hline Transformer terminal voltage & 1 per unit & 0.94 per unit \\
\hline Excitation current & 1 per unit & 1 per unit \\
\hline
\end{tabular}

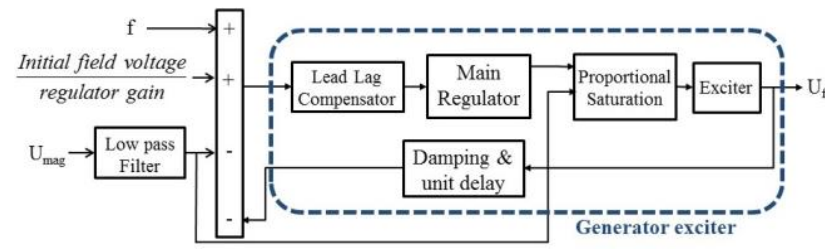

Figure 1. Schematic of cooperation enhancement control (U: generato terminal voltage, Uf: field voltage, f: network frequency) 
(a) Hydroplan

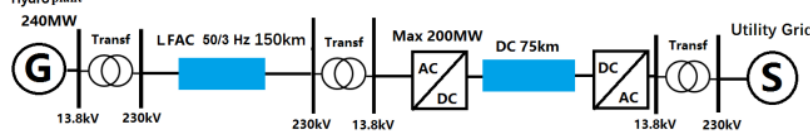

(b) Hydro plant

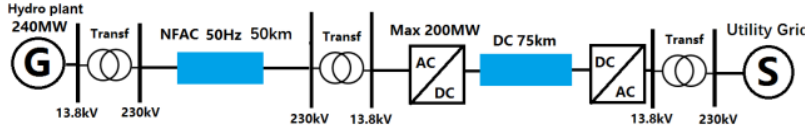

Figure 2. LFAC system + VSC-HVDC + Utility grid (Model 1); b) NFAC system + VSC-HVDC + Utility grid (Model 2)

In Model 1 depicted in Fig.2.a, the new control method is applied to the hydropower plant connected to a LFAC system. In Model 2 shown in Fig.2.b, conventional control is applied to the hydropower plant connected to a NFAC system. Frequency regulation in different scenarios will be compared to prove the feasibility and test the ability of the proposed control method. The values of the key parameters of both models are found in the Appendix; Tables III, IV and V.

\section{SCENARIOS AND RESULTS}

This section describes the three applied scenarios and the corresponding results of each scenario.

\section{A. Scenarios}

The applied scenarios are explained in Table II, where models 1 and 2 are displayed in Fig.2.a and Fig.2.b. Scenario 1 is designed to show how cooperation enhancement works when frequency drops. Scenario 2 examines whether all the equipment is still functional, when the frequency deviation is over large within a certain range, while Scenario 3 compares the depth of frequency drop in NFAC with LFAC under similar event. And the frequency event in all the scenarios is triggered by the sudden active power change of VSC station at LFAC or NFAC system.

\begin{tabular}{c|c|c|c}
\multicolumn{5}{c}{ TABLE II. APPLIED SCENARIOS } \\
\hline Scenario & Event & Location & Model \\
\hline 1 & $\begin{array}{c}\text { Active power set-point } \\
(0.45 \rightarrow 0.55 \text { at } \mathrm{t}=50 \mathrm{~s})\end{array}$ & $\begin{array}{c}\text { VSC-HVDC converter } \\
\text { station at LFAC }\end{array}$ & 1 \\
\hline 2 & $\begin{array}{c}\text { Active power set-point } \\
(0.45 \rightarrow 0.6 \text { at } \mathrm{t}=50 \mathrm{~s})\end{array}$ & $\begin{array}{c}\text { VSC-HVDC converter } \\
\text { station at LFAC }\end{array}$ & 1 \\
\hline 3 & $\begin{array}{c}\text { Active power set-point } \\
(0.45 \rightarrow 0.6 \text { at } \mathrm{t}=50 \mathrm{~s})\end{array}$ & $\begin{array}{c}\text { VSC-HVDC converter } \\
\text { station at NFAC }\end{array}$ & 2 \\
\hline
\end{tabular}

\section{B. Results}

In Fig.3.a, the voltages of hydro generator and converter station at LFAC side are proportional to frequency at LFAC side (Fig.3.c) to protect transformers from saturation. Due to the lack of secondary frequency regulation in the model, the frequency is not exactly $1 \mathrm{p} . \mathrm{u}$ before the events, and it does not recover to 1 p.u. after the event. (a)

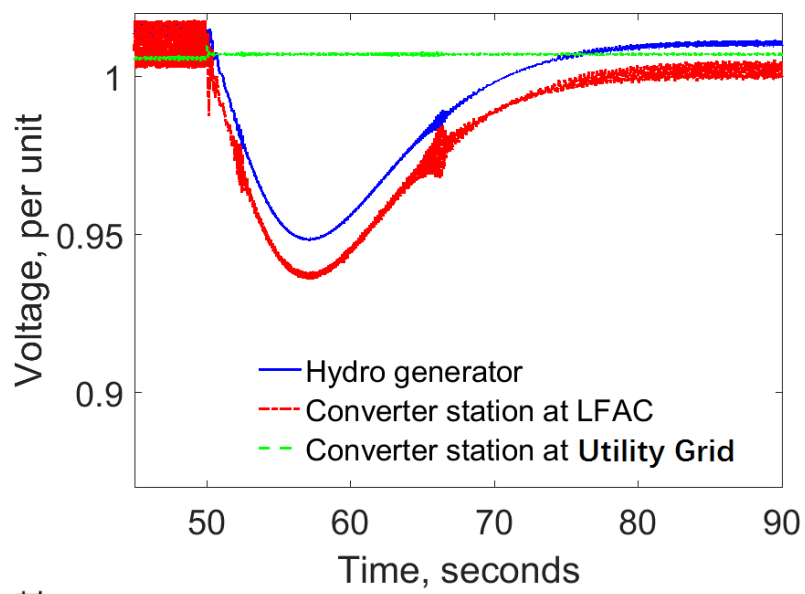

(b)

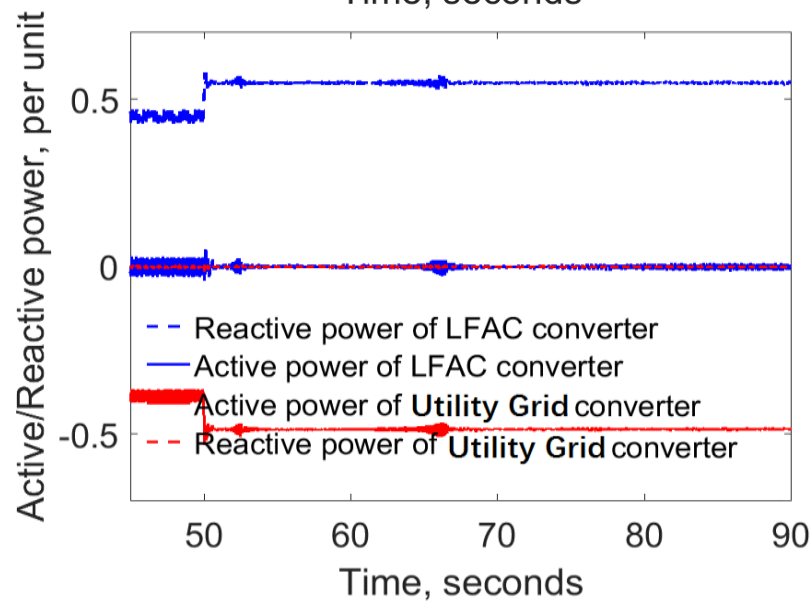

(c)

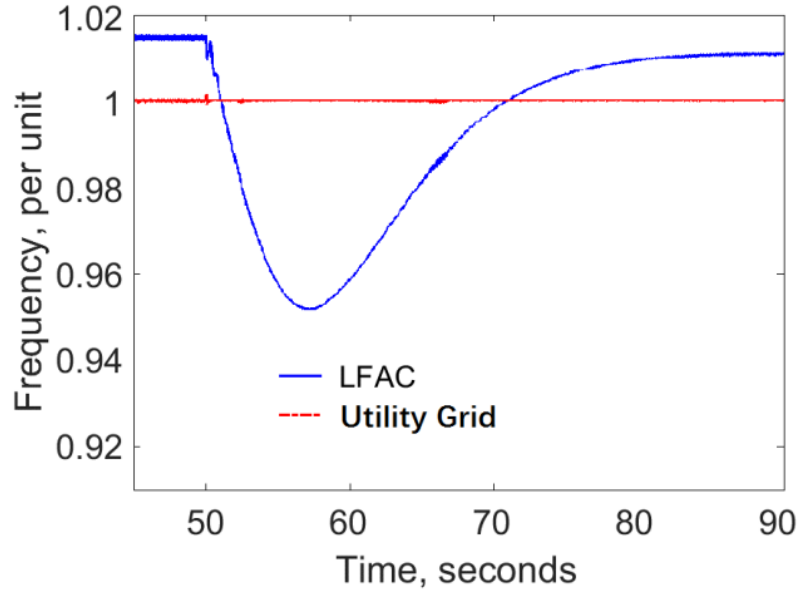

Fig.3. a) Voltage response b) Active and reactive power, and c) Frequency response at the LFAC system in Scenario 1

In Fig.3.b, to make long distance and large scale power transmission more economic, the delivered reactive power should be as small as possible, hence the configuration of the LFAC system power factor dependent on converter station is constant at unity. VSC -HVDC converter station can be regarded as a non-linear load, which can maintain the active power, when the voltage of LFAC system drops. In addition, active power and reactive power are controlled independently. The proposed cooperation enhancement can only be adopted when VSC-HVDC converter is the integrated power electronics interface to connect between the two systems of different frequencies. Otherwise, the voltage of 
transformer connected to either hydro generator or VSC converter station, will be higher enough to cause saturation problem, when the reactive power of frequency changer cannot be maintained around 0 p.u i.e. unity power factor.

When frequency event occurs, triggered by the sudden change in demand power, and due to the presence of DC link which decouples the grid from the LFAC, the voltage at grid is marginally affected as shown in Fig.3.a. In addition, the frequency of the grid is at its nominal level as shown in Fig.3.c, which ensures that the grid is not influenced by this frequency event and electricity quality of grid meets requirements in terms of frequency and voltage stability [23].

For Scenario 2, in Fig.4.a, since the voltage of the hydro generator is kept proportional to frequency by the modified set-point of the excitation system. However, when the frequency deviation excavates, the voltage drops leading to a change of reactive power of the converter station as shown in Fig.4.b. Comparing Scenarios 1 and 2, when the voltage of the converter station at LFAC system is below 0.95 p.u, the delivered reactive power is forced to be changed to maintain the voltage of converter station at LFAC system.

For Scenario 3, Fig.5 compares frequency responses of LFAC system in Scenario 2 where the cooperation enhancement is not able to reduce the time of primary frequency regulation in NFAC system. Conversely, the transformers at LFAC system can tolerate the frequency deviation for longer time under the proposed cooperation enhancement with the response of NFAC system in Scenario 3. It is equivalent to that the frequency regulation at LFAC is more flexible and safe to the integrated transformers under the proposed cooperation enhancement method.

In all the scenarios, the grid stability is marginally affected. However, the transformers at the hydropower station avoid saturation. In addition, the frequency at LFAC is able to tolerate a worse frequency dip to enable the provision of active power support to the grid applying the proposed cooperation enhancement control, which will be further investigated in future work.

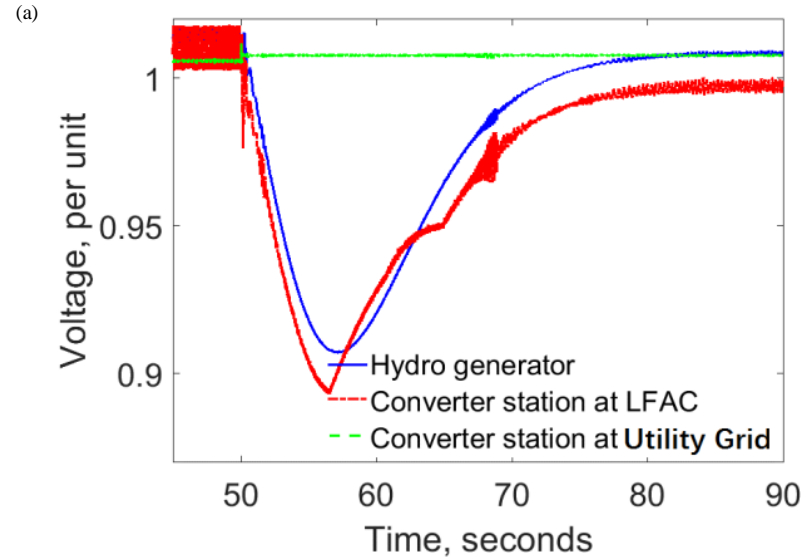

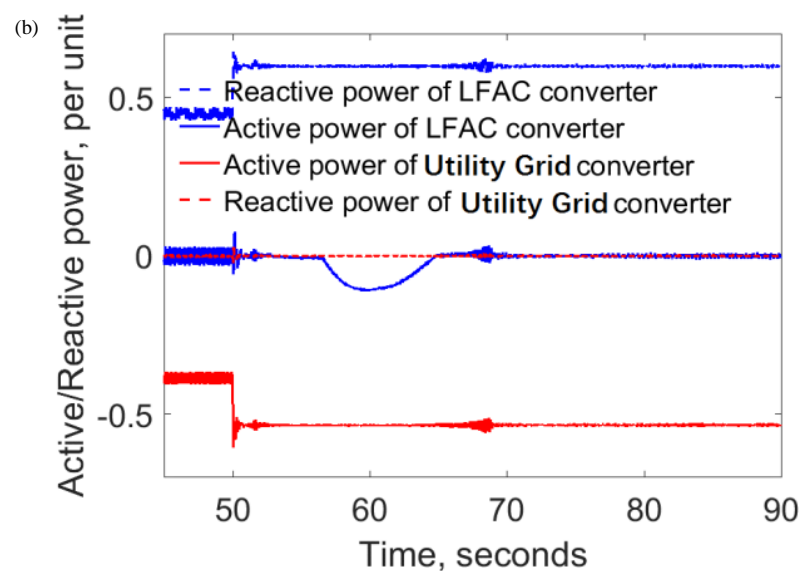

Fig.4. a) Voltage response and b) Active and reactive power in Scenario 2

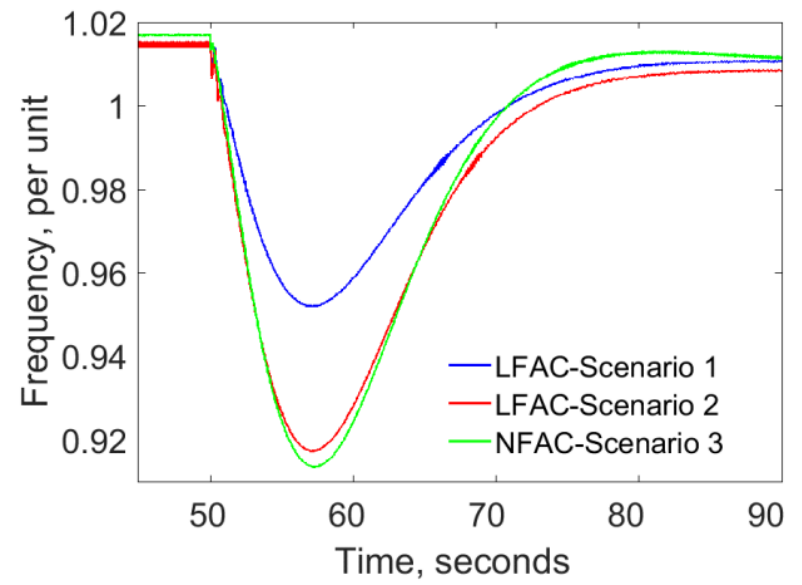

Fig.5. Frequency responses in all scenarios

\section{CONCLUSIONS}

A new control strategy named cooperation enhancement provides an alternative approach to maintaining the frequency stability in Low Frequency AC system (LFAC). In the Simulink model, the VSC-HVDC is adopted as a frequency changer to connect LFAC system and utility grid. Two case studies of LFAC system and one case study of NFAC system presented in this paper, show how cooperation enhancement control strategy strengths the frequency regulation ability of hydro generator at LFAC system. The results of various studies show feasibility of this control strategy, when a large frequency event happened at LF side: 1) the equipment at LFAC system is protected 2) the LFAC system recover to steady state 3) the electricity quality at utility grid is slightly influenced.

The benefits of this proposed concept is emphasizing the potential of frequency regulation ability of LFAC system; in addition, from the viewpoint of demand side, the hydropower plant behind VSC station can be regarded as an energy storage station. The future work includes an economic cost/benefit assessment to compare the proposed method to other conventional energy storage solutions. 


\section{ACKNOWLDGEMENT}

This work is funded by the FP7 project IRPWIND, agreement no 609795 .

\section{APPENDIX}

TABLE III. KEY PARAMETERS OF THE HYDRO TURBINE GENERATOR MODEL

\begin{tabular}{l|l|l|l}
\hline Automatic voltage regulator and exciter & \multicolumn{2}{|l}{ Turbine and governor } \\
\hline Gain (Voltage regulator) & 300 & Inertia coefficient & $3.2 \mathrm{~s}$ \\
Time constant $\mathrm{T}_{\mathrm{a}}$ & $0.001 \mathrm{~s}$ & Proportional gain & 1.163 \\
Gain $\mathrm{K}_{\mathrm{e}}$ (Exciter) & 1 & Integrator gain & 0.105 \\
Time constant $\mathrm{T}_{\mathrm{e}}$ & $0 \mathrm{~s}$ & Permanent droop & 0.5 \\
Damping filter gain $\mathrm{K}_{\mathrm{f}}$ & 0.001 & & \\
Time constant $\mathrm{T}_{\mathrm{f}}$ & $0.1 \mathrm{~s}$ & &
\end{tabular}

TABLE IV. KEY PARAMETERS OF THE INTEGRATED CONVERTERS MODELS

\begin{tabular}{l|l|l|l}
\hline \multicolumn{2}{l|}{ LFAC system } & \multicolumn{2}{l}{ NFAC and Utility Grid } \\
\hline Snubber resistance & $5000 \Omega$ & Snubber resistance & $5000 \Omega$ \\
Snubber capacitance & $1 \mathrm{e}-6 \mathrm{~F}$ & Snubber capacitance & $1 \mathrm{e}-6 \mathrm{~F}$ \\
Internal resistance & $1 \mathrm{e}-3 \Omega$ & Internal resistance & $1 \mathrm{e}-3 \Omega$ \\
DC Capacitor & $2.1 \mathrm{e}-04 \mathrm{~F}$ & $\begin{array}{l}\text { DC Capacitor } \\
\text { Phase reactor } \\
\text { Phase reactor }\end{array}$ & $2.1 \mathrm{e}-04 \mathrm{~F}$ \\
$\begin{array}{l}\text { (Resistance) } \\
\text { Phase reactor } \\
\text { (Inductance) }\end{array}$ & $0.0750 \Omega$ & $\begin{array}{l}\text { Resistance) } \\
\text { Phase reactor } \\
\text { (Inductance) }\end{array}$ & $0.0750 \Omega$ \\
& $0.0716 \mathrm{H}$ &
\end{tabular}

TABLE V. PLL SETTINGS AT DIFFERENT NETWORKS

\begin{tabular}{l|l|l|l}
\hline Parameter/Network & LFAC & NFAC & Grid \\
\hline Frequency & $16.67 \mathrm{~Hz}$ & $50 \mathrm{~Hz}$ & $50 \mathrm{~Hz}$ \\
Proportional gain & 10 & 20 & 60 \\
Integrator gain & 170 & 10 & 1400
\end{tabular}

VIII. REFERENCES

[1] A. Gad, "Utilizing STATCOM for power quality improvement under integration of wind farms into the unified grid," in 2016 Saudi Arabia Smart Grid (SASG), 2016, pp. 1-9.

[2] D. M. Patel, A. R. Nagera, and D. Y. Joshi, "Power quality improvement with Static Compensator on grid integration of wind energy system," in Nirma University International Conference on Engineering, 2011.

[3] I. E. Amin, M. F. Zia, and M. Shafiullah, "Selecting energy storage systems with wind power in distribution network," in 42nd Annual Conference of the IEEE Industrial Electronics Society, 2016.

[4] J. Tan and Y. Zhang, "Coordinated Control Strategy of a Battery Energy Storage System to Support a Wind Power Plant Providing Multi-Timescale Frequency Ancillary Services," IEEE Transactions on Sustainable Energy, vol. PP, pp. 1-1, 2017.

[5] W. Xiaolei, S. Lei, W. Fushuan, M. A. Salam, and S. P. Ang, "Control strategies of battery energy storage systems for smoothing wind power fluctuations," in 10th International Conference on Advances in Power System Control, Operation \& Management, 2015, pp. 1-4.

[6] H. S. Farmad and S. Biglar, "Integration of demand side management, distributed generation, renewable energy sources and energy storages," in CIRED 2012 Workshop: Integration of Renewables into the Distribution Grid, 2012, pp. $1-4$.

[7] S. Janocha, S. Baum, and I. Stadler, "Cost minimization by optimization of electricity generation and demand side management," in 2016 International Energy and Sustainability Conference (IESC), 2016, pp. 1-7.

[8] P. Taylor, H. G. Svendsen, C. Barbier, and C. Welby, "Demand for wind, maximising the value of wind power through demand side management," in CIRED Seminar 2008: SmartGrids for Distribution, 2008, pp. 1-4

[9] A. Y. Abdelaziz, M. A. El-Sharkawy, M. A. Attia, and E. F El-Saadany, "Optimal location of series FACTS to improve the performance of power system with wind penetration," in 2014 IEEE PES General Meeting | Conference \& Exposition, 2014, pp. 1-5.

[10] I. B. Jaoued, T. Guesmi, and H. H. Abdallah, "Power flow solution for power systems including FACTS devices and wind farms," in 14th Int. Conference on Sciences and Techniques of Automatic Control and Computer Engineering (STA), 2013, 2013, pp. 136-139.

[11] D. Yu, M. S. Li, T. Y. Ji, and Q. H. Wu, "Optimal voltage control of power systems with uncertain wind power using FACTS devices," in IEEE Innovative Smart Grid Technologies - Asia, 2016, pp. 937-941.

[12] W. Xifan and W. Xiuli, "Feasibility study of fractional frequency transmission system," Power Systems, IEEE Transactions on, vol. 11, pp. 962-967, 1996.

[13] W. Xifan, W. Xiaohui, and M. Yongqing, "Experiment on Grid-Connection Process of Wind Turbines in Fractional Frequency Wind Power System,", IEEE Transactions on Energy Conversion, vol. 30, pp. 22-31, 2015.

[14] J. Ruddy, R. Meere, and T. O’Donnell, "Low Frequency AC transmission for offshore wind power: A review," Renewable and Sustainable Energy Reviews, vol. 56, pp. 75-86, 2016

[15] J. Ruddy, R. Meere, and T. O’Donnell, "A Comparison of VSC-HVDC with Low Frequency AC for Offshore Wind Farm Design and Interconnection," Energy Procedia, vol. 80, pp. 185-192, 2015.

[16] C. N. Mau, K. Rudion, A. Orths, P. B. Eriksen, H. Abildgaard, and Z. A. Styczynski, "Grid connection of offshore wind farm based DFIG with low frequency AC transmission system," in Power and Energy Society General Meeting, 2012 IEEE, 2012, pp. 1-7.

[17] W. Fischer, R. Braun, and I. Erlich, "Low frequency high voltage offshore grid for transmission of renewable power," in Innovative Smart Grid Technologies (ISGT Europe), 2012 3rd IEEE PES International Conference and Exhibition on, 2012, pp. 1-6.

[18] P. Kundur, Power System Stability and Control. New York: McGraw-Hill Inc., 1994.

[19] N. A. Masood, Y. Ruifeng, and T. K. Saha, "A probabilistic index for estimating frequency response of a power system with high wind power penetration," in Electrical and Computer Engineering (ICECE), 2014 International Conference on, 2014, pp. 583-586.

[20] N. A. Masood, Y. Ruifeng, and T. Kumar Saha, "Estimation of maximum wind power penetration level to maintain an adequate frequency response in a power system," in International Conference on Electrical and Computer Engineering (ICECE), , 2014, pp. 587-590.

[21] A. B. T. Attya and T. Hartkopf, "Control and quantification of kinetic energy released by wind farms during power system frequency drops," IET Renewable Power Generation, vol. 7, pp. 210--224, 2013.

[22] M. Tsili and S. Papathanassiou, "A review of grid code technical requirements for wind farms," IET Renewable power generation, vol. 3, pp. 308-332, 2009.

[23] M. Kral, R. Gono, P. Moldrik, and M. Gono, "Quality analysis of electricity supply from small hydro power plants with Banki and pump turbines," in 16th International Scientific Conference on Electric Power Engineering (EPE), 2015, pp. 601-604. 